\title{
Facet Analysis of Anime Genres: The Challenges of Defining Genre Information for Popular Cultural Objects $\dagger$
}

\author{
Hyerim Cho*, Thomas Disher**, Wan-Chen Lee***, \\ Stephen A. Keating**** and Jin Ha Lee***** \\ *University of Missouri, 303 Townsend Hall, 221K, Columbia, \\ MO 65211, USA, <hyerimcho@missouri.edu> \\ ***University of Washington, Information School, Mary Gates Hall, Suite 370, Box 352840, \\ Seattle, WA 98195, USA, <leew23@uw.edu>, \\ ****1201 Elm Forest Drive, Cedar Park, TX 78613, USA, < stephen@ettugamer.com> \\ **, *****University of Washington, Information School, Mary Gates Hall 330Y-2 Gamer Lab, \\ 1851 NE Grant Ln., Seattle, WA 98105, USA, \\ **<tdisher@uw.edu>,*****<jinhalee@uw.edu>
}

\begin{abstract}
Hyerim Cho earned her $\mathrm{PhD}$ in information science from the University of Washington. Focusing on users, her research investigates diverse multimedia and pop-cultural information based on information science and media studies to provide enhanced recommendation and retrieval services. Her research interests include information needs and behavior, metadata, qualitative studies and mixed methods, and visual narrative materials such as graphic novels, anime, and video games.
\end{abstract}

Thomas Disher is a writer and stay-at-home-father. He holds a BA in English creative writing, with a linguistics minor from Seattle Pacific University and a MLIS from the University of Washington. Since earning his MLIS he has assisted Jin Ha Lee and the GAMER group with some of their research at the University of Washington. His research interests include metadata, classification systems, video games, anime, folklore, and linguistics. He also writes poetry and fiction.

Wan-Chen Lee is a $\mathrm{PhD}$ candidate at the Information School of the University of Washington, where she received her MLIS degree in 2014. She holds a BA in LIS from National Taiwan University. Her research interests include knowledge organization, classification theory, culture and classification, globalization and localization of cataloging and classification standards, and metadata.

Stephen Keating is a Senior User Researcher with Dell, with a master's in information science from the University of Washington, and a master's in media studies from The New School. Research interests include information organization, metadata, and semantic analysis, as well as a particular focus on the preservation of digital ephemera.
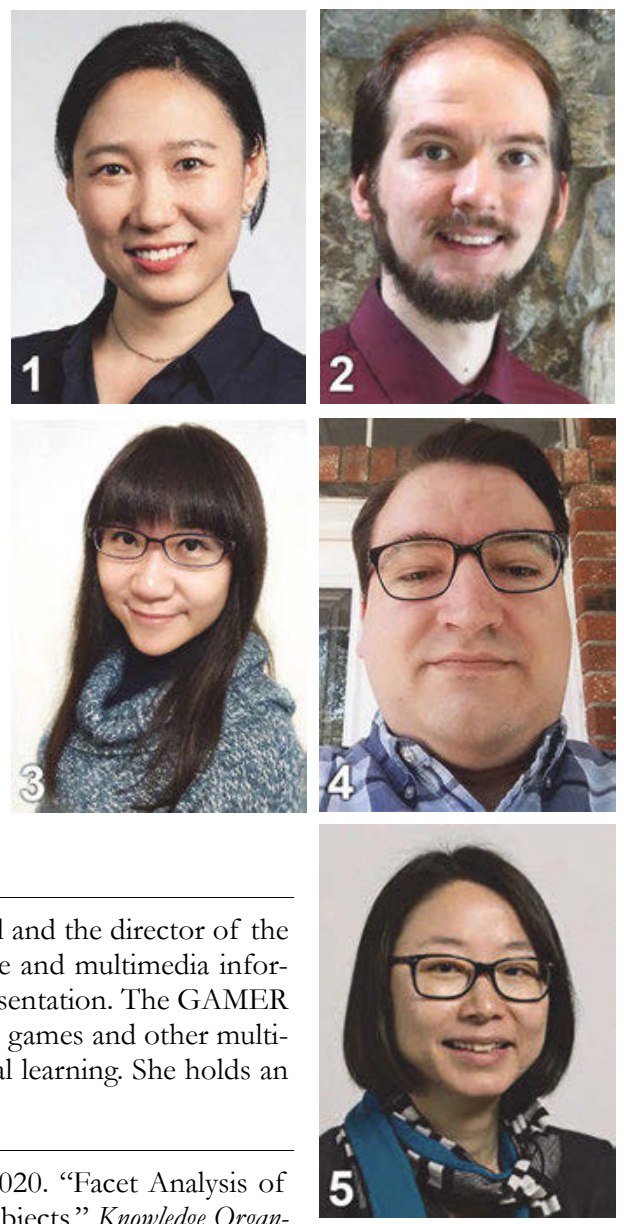

Cho, Hyerim, Thomas Disher, Wan-Chen Lee, Stephen A. Keating and Jin Ha Lee. 2020. "Facet Analysis of Anime Genres: The Challenges of Defining Genre Information for Popular Cultural Objects." Knowledge Organiqation 47(1): 13-30. 50 references. DOI:10.5771/0943-7444-2020-1-13.

Abstract: Anime, as a growing form of multimedia, needs a better and more thorough organization for its myriad unique terminologies. Existing studies show patrons' desire to search and get recommendations for anime. However, due to inadequate indexing and often confusing or inaccurate usage of terms, searching and acquiring recommendations remain challenging. Our research seeks to close the gap and 
make discovery and recommendations more viable. In this study, we conducted a facet analysis of anime genre terms that are currently used in thirty-six anime-related English-language databases and websites. Using a card sorting method with an inductive approach to the 1,597 terms collected, we identified and defined nine facets and 153 foci terms that describe different genres of anime. Identified terms can be implemented within different organizational systems including library catalogs, recommendation systems, and online databases to improve genre definitions and search experiences.

Received: 28 December 2017; Revised: 16 July 2018; Accepted: 2 August 2018

Keywords: anime, genre terms, facet analysis, foci terms, Japanese

† This article was originally published in Knowledge Organization v. 45, no. 6 (2018) on pages 484-99 DOI:10.5771/0943-7444-2018-6-484. Inexplicably most of the references were omitted at that time, and the appendix was incorrectly type-set. We apologize most profusely for our error and gratefully republish the article in toto with updated author biographical and contact information.-Editor-in-Chief.

\subsection{Introduction}

Interest in anime, a relatively recent multimedia medium in libraries, continues to increase artistically, commercially, and academically (Exner 2012; Fennell et al. 2013; Ressler 2016). The anime industry has been growing for the last five years (AJA 2016), and the total market value of the anime industry in 2015 was 18.1 billion US dollars, a $12 \%$ year on year increase from 2014 (Ressler 2016).

Anime is commonly defined as Japanese animation, or animation produced in Japan, although to Japanese, "anime covers all animation regardless of provenance" (Richmond 2009, 2). Davis (2016, 35) defines it as "Japanese limited-animation, which is a form of animation that utilizes fewer frames than the classic Disney animation and a variety of other cost-saving techniques," focusing on economic and technical aspects. Brenner $(2007,29)$ more broadly defines it as:

Animated films produced in Japan for a Japanese audience. The word itself comes from the word animeshon, a translation of the English word "animation." This term encompasses all animated titles including feature films, television shows, and original video animation (OVA) released to the home entertainment market.

Brenner's definition, particularly "animated films produced in Japan for a Japanese audience," is debatable due to the fact that it is difficult to draw a clear conclusion about where anime is produced, and, especially today, anime is not only for a Japanese audience but an international one as well.

Denison (2015, 2 emphasis original) argues that "anime is not just a genre any more than it is simply a kind of animation or a product of only Japanese culture." Denison expands these limited definitions by saying that "anime needs to be understood more broadly as a cultural phenomenon whose meanings are dependent on context." This expanded concept of anime views it as a "medium," "multi- media," and "part of a range of (trans)national media cultures" (Denison, 22).

Although recently it is becoming more difficult to draw a line between what is anime and what is not, in general, anime has several unique characteristics that are distinguishable from Western animation. Levi (2013) states that sadness, environmentalism, and terror are unique themes found in anime, and Davis (2016) provides an interview with Robert Napton, a graphic novel writer and former employee at Bandai Entertainment, who states that plot and narrative style are anime's main appeals to its audience, an audience that includes female adults, who were often excluded in Western comics and animation culture.

Despite the growing prevalence of and demand for anime, current organizational systems for anime are lacking, especially when describing genre information. A survey conducted by Exner $(2012,34)$ showed this clearly, as the majority of library patron respondents expressed "the desire for a greater quantity or variety of support" for accessing anime or "more robust genre cataloguing," although some respondents also indicated that they were "categorically not interested in anime or manga through the library." Strengthening the organizational access points for and information about anime titles would help address such user experience requests and facilitate access to existing collections.

As with other narrative and visual narrative materials, an important access point for anime is genre information. Sardar and Van Loon $(2015,49)$ define genre as "categories of media products; specific types of books, film, television and radio programs. Genres are identified by their conventions, which the audience recognizes through regular contact. The term originated in literary criticism but was adopted by cinema studies. Television is exclusively genre-led." In a previous study on investigating anime users' information needs for recommendations (Cho et al. 2017), genre was one of the most frequently mentioned features used to get recommendations (ranked third among nineteen features identified). Lee, Shim, and Jett (2015) also had similar findings: genre was the second 
most mentioned feature when Korean anime users sought recommendations.

However, despite such common usage, genre in anime remains highly ambiguous. Even some anime fans may not be familiar with some of the genre terms in the information systems, such as sekai-kei (world-type) and iyashikei (healing). In addition, whether an anime belongs to genre A or B is often unclear. As an example, in a previous study (Cho et al. 2017), we defined genre as "categories of anime characterized by similarities in form, style, or subject matter, including typical genre labels that are universally used by anime users," but how real users interpreted genre varied. What some users called genre was considered a theme or trope by other users. Even when users used the same genre term, the elements they expected were often different.

In a similar vein, current information systems have shown several limitations in providing anime's genre information. While there are a considerable number of usergenerated tags about anime genres online, the tags are often confusing and ambiguous, with little consensus for the definitions of many anime genres. Anime and manga tend to use genre terms to indicate the target audience, such as seinen (young men/youth). Some users use the seinen label to describe anime generally made for mature audiences, others use it for anime with complex plots or serious issues regarding life or society, and still others use the term to describe anime with more violent or sexual content. Due to different understandings and ambiguous definitions of the same term, various anime databases commonly show conflicting results when searching for the same genre term. Crunchyroll (http://www.crunchyroll.com/videos/anime/genres) mostly shows anime with mature content under the genre filter "Seinen/Mature" (as the genre term itself already indicates), but Anime-Planet (2017) and MyAnimeList (https://myanimelist.net/anime.php) yield results including Mushi-shi (2005) and Haven't you heard? I'm Sakamoto (2016), which are both listed in Crunchyroll but not classified as seinen.
Due to definitional ambiguity, it is now common for English-speaking anime users to directly adopt Japanese terms to describe anime genres, such as bishöjo (beautiful girls) and iyashikei. Considering user warrant, literary warrant, and scholarly usage (Svenonius 1989), information systems may continue to utilize Japanese-originated genre terms. However, using foreign language terms as index terms risks confusing users who do not understand the language and could be problematic for both knowledge organization and information retrieval in the long run.

Additionally, while genre terms are often used across different multimedia, such as comic books, video games, and films, they are not readily usable in anime. Poitras $(2002,34)$ states that "genre in anime is a tricky subject. Japanese and American animation genres don't exactly parallel one another; nor are the expressions of genre in Japan quite like those found elsewhere in the world." Since anime originated in Japan, different cultural notions are interwoven in its expressions, including characters, plots, and settings of anime. Considering the confusing interpretations, ambiguous meanings, and cultural elements, a more agreed-upon, clearer method for organizing anime genre information is required.

Having agreed-upon definitions of anime genre information is a vital first step in creating a reliable taxonomy. To fully understand the uses of current anime genre terms and to provide a more robust and clearer way to describe diverse anime genre information, this study explores the following research questions:

- RQ1: What are the genre terms of anime that are currently used, and what kinds of information features are represented in these labels?

- RQ2: What are the facets and foci that describe diverse layers of anime information features currently embedded in anime genre terms?
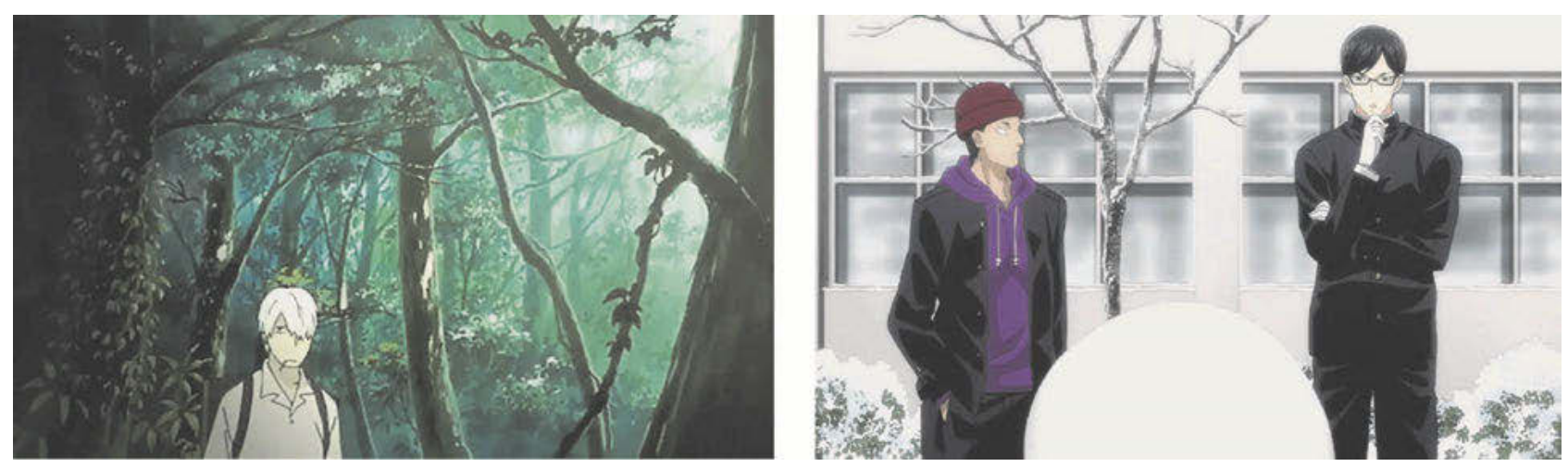

Figure 1. Screenshots of Mushi-shi (2005) and Haven't you beard? I'm Sakamoto (2016), from left to right. 


\subsection{Previous studies and practices}

The current organization of anime genres reveals how individual anime frequently fit into multiple genre terms. Both Poitras (2002) and Richmond (2009) point out that anime itself is not a genre as it is sometimes called. Poitras (2002, 7 emphasis original) states that anime "is in reality an art form that includes all the genres found in cinema, from heroic epics and romances to science fiction and comedy," while Richmond (2009, v) says that "anime is a medium, not a genre: the cute antics of Hello Kitty and Pokémon, and complex psychological thrillers such as Perfect Blue are all part of the anime universe." Robbins (2014) and Halsall (2004) also discuss anime as a medium that spans multiple genres.

Poitras (2002) dedicates a chapter to anime genres, discussing several genres and subgenres. The genre/subgenre ordering of the chapter suggests a hierarchical organization. However, Poitras $(2002,34)$ points out the problem with assigning only one genre term to an anime:

Gundam 0080 (1989) can be described as a giant robot anime. But such a description does not do justice to the story's many layers of complexity dealing with family problems, civilians caught up in war, and friendship between a child and soldier, not to mention the sheer tragedy of death and destruction brought on by war. Gundam 0080 is no more just a giant robot anime than War and Peace is just a war novel.

Poitras illustrates the limitations of single identifiers inherent in a hierarchical taxonomy. Similarly, Richmond (2009) details genres with some subgenres and indicates a hierarchical organization. For instance, Richmond includes genres like "science fiction" (200), "fantasy and fables" (203), "historical dramas" (217), and "sports, martial arts and contests" (230); some genres are further subdivided, such as "fantasy and fables" into "oriental-influenced," "Japanese folk tales," "western-influenced," and "magical girl."

Moreover, there is a wide variety of disparate labeling systems used by commercial websites. The diversity of browsing systems illustrates a lack of uniform methods of reference for anime and suggests patterns for structuring coherent genre identification (Table 1). Of the five sample websites, four of them use some sort of Boolean operation to allow users to search by multiple genre terms, although only two, IMDb (http://www.imdb.com) and Crunchyroll, enable a Boolean "and" operation which acknowledges that a single title can encompass multiple genres. IMDb also includes the greatest number of genre terms (twenty-seven), while Amazon lists the fewest (six). Each sampled site provides additional filters to allow users to sort and search by other elements, such as popularity,

\begin{tabular}{|c|c|c|c|c|c|}
\hline & Amazon & IMDb & Crunchyroll & $\begin{array}{c}\text { Funimation } \\
\text { (https://www. } \\
\text { funimation.com/ } \\
\text { genre/) }\end{array}$ & $\begin{array}{c}\text { VIZ Media } \\
\text { (https://www.viz. } \\
\text { com/watch) }\end{array}$ \\
\hline $\begin{array}{l}\text { Boolean } \\
\text { Operators }\end{array}$ & OR & AND & AND & OR & None \\
\hline $\begin{array}{l}\text { Genre } \\
\text { Terms }\end{array}$ & $\begin{array}{l}\text { Action; } \\
\text { Children's; } \\
\text { Comedy; } \\
\text { Fantasy; } \\
\text { Horror; } \\
\text { Science Fiction }\end{array}$ & $\begin{array}{l}\text { Comedy; } \\
\text { Sci-fi; } \\
\text { Horror; } \\
\text { Romance; } \\
\text { Action; } \\
\text { Thriller; } \\
\text { Drama; } \\
\text { Mystery; } \\
\text { Crime; } \\
\text { Animation; } \\
\text { Adventure; } \\
\text { Fantasy; } \\
\text { Comedy-Romance; } \\
\text { Action-Comedy; } \\
\text { Superhero }\end{array}$ & $\begin{array}{l}\text { Action; } \\
\text { Adventure; } \\
\text { Comedy; } \\
\text { Drama; } \\
\text { Ecchi; } \\
\text { Fantasy; } \\
\text { Historical; } \\
\text { Mecha; } \\
\text { Romance; } \\
\text { Science Fiction; } \\
\text { Seinen/Mature; } \\
\text { Shoujo; } \\
\text { Shounen; } \\
\text { Slice of Life; } \\
\text { Sports }\end{array}$ & $\begin{array}{l}\text { Action/Adventure; } \\
\text { Comedy; } \\
\text { Drama; } \\
\text { Fan Service; } \\
\text { Fantasy; } \\
\text { Horror; } \\
\text { Live-Action; } \\
\text { Psychological; } \\
\text { Sci-Fi; } \\
\text { Shoujo; } \\
\text { Shounen; } \\
\text { Slice of Life }\end{array}$ & $\begin{array}{l}\text { Action-Adventure; } \\
\text { Comedy; } \\
\text { Drama; } \\
\text { Family; } \\
\text { Fanasy; } \\
\text { Horror; } \\
\text { Martial Arts; } \\
\text { Mystery; } \\
\text { Romance; } \\
\text { Science Fiction; } \\
\text { Sports; } \\
\text { Supernatural; } \\
\text { Thriller }\end{array}$ \\
\hline $\begin{array}{l}\text { Addi- } \\
\text { tional } \\
\text { Filters }\end{array}$ & $\begin{array}{l}\text { Format; } \\
\text { Release date; } \\
\text { Franchise; } \\
\text { Actor; } \\
\text { Director; } \\
\text { Customer rating }\end{array}$ & $\begin{array}{l}\text { Popularity; } \\
\text { Alphabetical; } \\
\text { IMDb rating; } \\
\text { IMDb votes; } \\
\text { US box office; } \\
\text { Runtime; } \\
\text { Release date }\end{array}$ & $\begin{array}{l}\text { Alphabetical; } \\
\text { Popularity; } \\
\text { Updated; } \\
\text { Silmulcasts; } \\
\text { Seasons }\end{array}$ & $\begin{array}{l}\text { Rating; } \\
\text { Version; } \\
\text { Date added; } \\
\text { Alphabetical; } \\
\text { Popularity }\end{array}$ & $\begin{array}{l}\text { Dubbed; } \\
\text { Subtitles; } \\
\text { Series }\end{array}$ \\
\hline
\end{tabular}

Table 1. Examples of current anime information systems. 
customer ratings, or release date. Each website includes different search terms and structures its search system differently, creating unnecessary obstacles for users attempting to locate anime. These search methods acknowledge the multitude of information types that users find desirable when either browsing or seeking specific titles. A system able to efficiently and completely represent a broad variety of information about anime titles in a collection might prove useful to both distributors and users.

The debate on the notion of genre has continued for a long time (Rafferty 2012; Frow 2006; Cobley 2005). Frow (2006) and Cobley (2005) trace the theoretical basis of genre to Aristotle and Plato. Discussing fiction librarianship, Rafferty $(2012,557)$ states that genre "has pragmatic and operative power, but it is a concept that as a categorizing principle has been subject to debate from within literary and cultural theory." Rafferty (564) also suggests that the social semantic web and user generated tags can be a future solution for developing genres of fiction, arguing that "even within the discourse of literary theory there has been a shift from the idea that genre is based entirely on literary warrant, a viewpoint that underpinned many early approaches to genre theory, to a viewpoint that sees the interaction between the work and the interpreting reader as the basis for meaning-making." Scholarly tradition has thus begun to lean toward allowing user preferences to shape genre terms and related metadata.

Considering the ambiguous nature of genre, this study applies facet analysis, an analytic approach rooted in the knowledge organization domain (Vickery 1960), to more clearly and rigorously classify anime's genre information. Facet analysis technique has been used to develop various knowledge organization systems, including classification systems, thesauri, and taxonomies, as well as website architectures and visual/navigational information structures (Shiri 2014). It identifies top-level characteristics of division (i.e., facets) and allows combination of values (i.e., foci) from within these characteristics of division (Green 2017). As Shiri $(2014,358)$ noted, facet analysis has proved to be useful to describe the "various characteristics, attributes and aspects of complex, compound and multi-faceted topics." Since genre has long been understood as both complex and ambiguous, we used a facet analysis approach for this study to explore and collect the different aspects of genre. Without having a comprehensive grasp of all possible aspects of genre, we cannot propose an enumerative classification of it. From this perspective, facet analysis provides a lens to view genre as a set of facets, which are "semantically cohesive categories" (Svenonius 2000, 143) and "component parts or 'the faces' of a phenomenon” (Smiraglia and Henry 2016, 155).

Further, we adopt facet analysis for its ability to identify different aspects of genre for both indexers and users
(Hjørland 2013). For indexers, the faceted schema provides a structure for describing anime. By following the structure, an indexer is less likely to miss important facets. For users, the list of facets presents possible access points of an information system and helps them formulate queries. In addition, as Green (2017) points out, the main advantages of facet analysis are its strong link to a field's literature and its ability to address organizational needs. Because our data sources are information systems that emphasize anime retrieval and discovery, and because the primary objective of this study is to contribute to the improvement of both anime description and retrieval, we believe that the facet analysis approach is appropriate.

Following the basic steps for facet analysis (La Barre 2010), we explore multiple components of anime genre. Starting from collecting genre terms from information systems for anime, we develop facets and sub-facets after data cleaning and organizing the foci, and all the concepts derived from the analysis were mutually exclusive (Slavic and Davies 2017). Definitions of all facets and some of the foci terms are described in section 4. Findings and Discussion.

\subsection{Research method}

As emphasized in the literature review, anime genre is complex and multifaceted. There is no consensus for its definition. Further, genre is often used interchangeably with terms like theme and plot. The distinctions between these terms are ambiguous. The study's purpose is to examine the concept of genre in anime and identify prominent aspects. Hence, we applied facet analysis to anime genre terms collected from 36 English websites (3 additional Japanese websites were observed to see if there is any important information missing from English websites, but they were not part of the analysis). Applying an inductive approach, we identified nine major facets from 1,597 terms using a card-sort method.

\subsection{Data collection}

The data collection process is visualized in Figure 2.

We collected anime genre terms from popular websites and blogs. Sources include information systems providing anime information, such as Anime-Planet. These systems allow users to browse and search anime by genre. Other sources list or define anime genre terms, such as Wikipedia and Senpai Knows.

The criteria for source selection are language and term variety. To understand anime genre terms in the context of English-speaking audiences, the language criterion set the focus of this study at sources which provide English-language anime genre terms. As a preliminary attempt to 


\section{Term Collection}

- From 36 anime-related English websites and databases

- 1,597 genre terms collected

\section{Term Counting}

- Selected terms that appeared in more than 1 source

- Classified compound terms and sub-genre terms for further analysis

\section{Data Cleaning}

- Merged conceptually same terms based on existing literature and user warrant

- Resulted in a total of 643 genre terms

\section{Facet Creation}

- Further data cleaning and term merging

- Identified 9 facets and 13 subfacets

\section{Final Refinement}

- Defined each facet and sub-facet

- Assigned foci terms to each facet

- 153 foci in total determined and organized

Figure 2. Data collection process.

compare English and Japanese anime genre terms, besides the thirty-six English language sources, we examined three Japanese sources for reference (i.e., Kinokuniya web store, Tsutaya web store, and d Anime store), all of which are major online stores selling anime DVDs and Blu Rays or are streaming providers. Another criterion is term variety. While identifying prominent facets of anime genre through a bottom-up approach, we selected sources with a variety of anime genre terms. There is a range of seven to 283 genre terms, with subdivided terms in each source selected.

The principles for term collection are transcription and context preservation. For sources that organize genres hierarchically, we collected the terms of each subdivision and preserved the context. For instance, both "sports" and "game" are top level genre terms; and both terms have the subdivision term "baseball." In this case, we collected four terms: "sports;" "sports—baseball;" "game;" and, "game_baseball." Documenting the hierarchy in this way helps preserve the context and meaning of a subdivided term. We collected 1,597 terms from thirty-six English-language sources.

\subsection{Data cleaning}

There are five stages of data cleaning. The first stage is merging duplicates, in which identical terms are merged. After the first stage, we made the terms into cards and conducted card sorting for the second and third stages. The second stage is merging variant forms. Variant forms of the same term may differ in spacing, usage of hyphen, and Romanization (e.g., lolicon and rolikon [Lolita complex]). Obvious typos are also merged at this stage. The third stage is merging translations and romanizations. For instance, we merged magical girl with mahou shoujou. After the first three stages of data cleaning, we sorted the terms into three groups: simple terms, compound terms, and subgenre terms. Simple terms describe one concept (e.g., mystery, love triangle, mind-twisting, piloted robot). Compound terms address more than one concept (e.g, action/adventure, military and warfare, anime and manga). Sub-genre terms refer to terms including hierarchical structure. For instance, "game-baseball" specifies that the sub-genre term "baseball" is subdivided under "game." Considering the complexity of the three types of terms, 
we used simple terms as the foundation for facet development.

The fourth stage is merging similar simple terms with different levels of specificity. For instance, we grouped afterlife, underworld, heaven, hell, and makai (world of spirits; hell) and labeled them as "afterlife." In this case, "afterlife" was selected as the preferred term to represent this group of similar terms. Another example is using "game" to represent different types of games, including "board games," "online computer gaming," "high stakes game," and "action game." In this stage, we merged similar or closely related terms with different levels of specificity and labeled the group with a broader term. The broader term is the preferred term encompassing the concepts of the group of terms. The data cleaning in this stage adjusts the granularity of the data. Instead of focusing on the different meanings of similar or closely related terms, this approach directs our focus to identify prominent general concepts about anime genre. The fourth stage thus establishes the foundation of facet analysis for this study.

The fifth stage is standardization. We applied three principles for selecting and standardizing preferred terms. The first principle focuses on the part of speech and singular or plural forms. Preferred terms are terms with the highest frequency. If there is no prominent preference identified, we use plural nouns. The second principle standardizes the representation for romanizations and English terms. For terms having both Japanese romanization and English translation, we use romanization and place the English term in parenthesis. An example is "kodomo (children)." The third principle focuses on disambiguation. For terms encompassing multiple concepts, we use parenthetical qualifiers to disambiguate. For instance, the concept "gekiga" refers to a combination of a type of plot and a realistic visual style. We use "gekiga (Plot)" and "gekiga (style)" to differentiate the specific aspect of focus.

The five stages of data cleaning render a total of 643 terms, including 538 single and compound terms and 105 sub-genre terms.

\subsection{Data analysis}

There are two phases in the data analysis process. The first phase develops facets and sub-facets using a bottom-up approach. We examined the preferred terms that appeared more than once after data cleaning. These terms are the foci. Based on the foci, we developed nine facets and thirteen sub-facets. After the first phase, each focus was assigned to one facet and one facet only. Foci assignment tests the mutual exclusivity of the facets.

The second phase tests the exhaustivity of the facets with compound terms and sub-genre terms. As defined in the data cleaning section, compound terms and sub-genre terms include more than one concept. We used the facets and foci to describe all concepts presented in the genre terms collected and adjusted terms accordingly.

We recognize that new genre terms continue to emerge and that the genre terms collected are not comprehensive. However, the purpose of this study is not to provide an exhaustive list of genre terms. Instead, we propose a faceted structure to organize anime genre descriptors. Through collecting various terms, the goal is to identify prominent dimensions of anime genre. We present the results of this study by developing mutually exclusive and collectively comprehensive facets that are flexible enough for expansion. Further, we collect existing terms that users already apply for anime information, organization, and retrieval. Some terms present challenges and reaffirm the complex nature of genre. We will discuss some of these challenges below.

\subsection{Findings and Discussion}

\subsection{Overview of Developed Facets}

We identified nine facets and 153 foci terms. Each facet represents a different aspect of anime, mutually exclusive from other facets. The facets, the number of foci within each facet, and the examples of foci are shown in Table 2. The complete list of subject foci terms is presented in an appendix.

Some of the facets, such as "setting," "plot/narrative," "subjects," "feature" and "production" have sub-facets to represent specific hierarchical relationships. For example, "setting" has three sub-facets: "setting-time," "setting-situational," and "setting-place." All the foci of "setting" belong to one of these sub-facets. In the case of "plot/narrative," most of its foci directly belong to the main facet, "plot/narrative," but one of its foci, "romance," is further divided into "romance-types" and "romance-multiple people."

It was challenging to construct facets that:

1) distinguish clearly among the component parts;

2) are relevant to the purpose, subject, and scope of the classification;

3) represent characteristics of division that can be measured;

4) only represent single characteristics of division;

5) are mutually exclusive to each other; and,

6) are derived based on the nature of the subject being classified (Spiteri 1998).

Though we are satisfied with the facets presented in this study, we acknowledge that classifying subjective information of a cultural medium will evolve over time. To accommodate the dynamic nature of anime genre terms, the 


\begin{tabular}{|c|c|c|}
\hline Facet & $\begin{array}{l}\text { Number of } \\
\text { Foci }\end{array}$ & Examples of Foci \\
\hline Audience & 6 & $\begin{array}{l}\text { Josei (Women), Seinen (Young Men/Youth), Shōnen (Boys), Shōjo (Girls), Kodomo } \\
\text { (Children), Family }\end{array}$ \\
\hline Setting & 15 & $\begin{array}{l}\text { - Setting-Time: Cyberpunk, Steampunk, Historical } \\
\text { - Setting-Situational: Fantasy, Apocalypse, Science Fiction, Science Fantasy, Dystopia } \\
\text { - Setting-Place: Isekai (Parallel Universe), Western, Restaurants/Stores, Space Opera, } \\
\text { Space, School, Afterlife }\end{array}$ \\
\hline Mood & 7 & Tragedy, Thriller, Comedy, Psychological, Horror, Suspense, Iyashikei (Healing) \\
\hline Character & 32 & $\begin{array}{l}\text { Detectives, Police, Students, Idols, Pirates, Hunters, Hybrids, Cyborgs, Androids, Ro- } \\
\text { bots/Mecha, Bishōjo (Beautiful Girls), Bishōnen (Beautiful Boys), Monsters, Aliens, } \\
\text { Vampires, etc. }\end{array}$ \\
\hline Plot/Narrative & 21 & $\begin{array}{l}\text { Slice of Life, Coming-of-Age, Adventure, Mystery, Absurd, Romance, etc. } \\
\text { - Plot/Narrative-Romance-Types: Bara (Boys' Love for Male Audience), Age Gap, } \\
\text { Shōnen Ai/Yaoi (Boys' Love), Shōjo Ai/Yuri (Girls' Love) } \\
\text { - Plot/Narrative-Romance-Multiple People: Love Triangle, Harem/Reverse Harem }\end{array}$ \\
\hline Subjects & 47 & $\begin{array}{l}\text { Game, Vehicles, Cooking, Time Travel, Magic, Virtual Reality, Politics, Work Life, } \\
\text { Crime, Arts, Natural Disaster, Sports, etc. } \\
\text { - Subjects-Sports: Wrestling, Baseball, Gymnastics, Boxing, Martial Arts, Archery, etc. }\end{array}$ \\
\hline $\begin{array}{l}\text { Association with Other } \\
\text { Works }\end{array}$ & 5 & Parody, Novel, Comics, Manga, Documentary \\
\hline Feature & 7 & $\begin{array}{l}\text { Action Scenes, Fan Service, Power Suits, Henshin (Transformation) } \\
\text { - Feature-Action Scenes-Types: Proxy Battles, Swordplay, Gunfights }\end{array}$ \\
\hline Production & 13 & $\begin{array}{l}\text { - Production-Techniques: CG Animation } \\
\text { - Production-Styles: Chibi (Super Deformed), Gekiga (Style) } \\
\text { - Production-Regions: Foreign Anime, Cartoon } \\
\text { - Production-Agents: Voice Actors } \\
\text { - Production-Formats: ONA (Original Net Animation), Special (SP), OVA, Short } \\
\text { (Length), Movies, Series } \\
\text { - Production-Languages: Dubbed }\end{array}$ \\
\hline
\end{tabular}

Table 2. Anime genre facets with examples of genre terms.

proposed facets are flexible. New genre terms may be added to the faceted schema, and the structure can be extended as well.

Note that some of the foci are written in Japanese and have a translated meaning inside of the parentheses beside the original Japanese term, such as "josei (women)" and "iyashikei (healing)." As discussed above, it is very common in the current US anime community for anime fans to use Japanese terms to describe genre information. Considering user warrant (Svenonius 1989), we could have adopted the current term practices directly into our faceted schema. However, for the faceted schema to be more intuitive and user-friendly to people who are not familiar with anime and Japanese, we decided to have a translated meaning together with the commonly used Japanese genre term to increase ease of use for English language indexing.

\subsection{Audience}

The Audience facet encompasses the target demographic of the anime. Thus, the foci terms tend to originate from the creators, publishers, and/or distributors of anime. The reason for including the target audience as a facet is twofold.
First, it draws on existing categories for organizing anime. On Crunchyroll, for example, shōnen, shöjo, and seinen are included as genres. Anime-Planet and MyAnimeList use shönen, shöjo, seinen, and josei, with MyAnimeList also providing "kids" as a genre term. Denison $(2015,24)$ points out that "anime is for everyone in Japan, but not every show is aimed at everyone- there are genres for most age groups, genders and sexual orientations, and anime's genres often reflect industrial categories" and that the terms most frequently applied to anime in Japan come from the manga descriptors for intended audiences. Denison adds that "in Japan, shōnen and shōjo are themselves, therefore, sprawling transmedia categories whose meanings can seem confusing or seemingly arbitrary." So, while there is strong literary and user warrant for the "audience" facet's foci terms, the boundaries between the categories they pull from are not always clear.

Second, the "audience" facet highlights that the intended demographic of an anime can have an impact on the content. That is, there are various tropes associated with each of the foci. Shönen anime often incorporate fighting and male protagonists, while shöjo anime often feature romantic subplots and female protagonists. However, 
it is important to note that the actual demographic watching anime can differ from the intended demographic.

- Kodomo (Children) is for anime intended for children with an upper bound of late elementary school age to junior high school age;

- Family is for anime intended for all ages based on a hypothetical family containing young children to adults/elderly;

- Shōnen (Boys) is for anime intended for teenage boys;

- Shōjo (Girls) is for anime intended for teenage girls;

- Seinen (Young Men/Youth) is for anime intended for young men; and,

- Josei (Women) is for anime intended for women.

Because "kodomo" and "family" anime both have young children as all or part of the intended demographic, the boundary between them is difficult to determine. Richmond (2009, 201) calls My Neighbor Totoro and Doraemon anime for children in his discussion of anime demographics. However, IMDb lists the genres of My Neighbor Totoro as "animation, family, fantasy" and those of Doraemon as "animation, comedy, family, sci-fi.". The Japanese Wikipedia entries for the 1979 (Wikimedia 2017a) and 2005 (2017b) Doraemon anime further complicate matters by listing both as falling under the "family/intended for general public anime" (famiri ippanmuke anime ファミリー・一般向けアニメ) and “science fiction gag anime” (SF gyagu anime SFギャグアニメ) genres. One final wrinkle is that the Japanese Wikipedia page for "intended for children anime" (Kodomomuke anime 子供向けアニメ) links to the 2005 Doraemon anime from its section on the characteristics of "Kodomo" anime for infants and young children (2017b). If the creator, publisher, or distributor of an anime that could fall into either "kodomo" or "family" does not provide the intended demographic, then assigning either "kodomo" or "family" to an anime becomes a subjective decision based on whether the cataloger feels the anime is strictly for young children.

Seinen (青年) as a term can mean “youth," though typically it is used to refer to young men. Denison $(2015,24)$ illustrates the difficulty of the term by translating it two different ways on the same page: first as "young adult" and later as "aimed at adult men." It may be the case that some of the sites are using the term in the broader sense of referring to all youth regardless of gender. However, Richmond (2009), Brenner (2007), and Poitras ([2007] 2010) use the term in the narrower sense of young men, which is supported by several Japanese dictionaries (Kodansha's 1999; Kodansha's 2002; Breen 2018). Another difficulty with seinen arises because most English-language sites do not provide the kanji for Japanese terms. Seinen is also the pronunciation of 成年, meaning “adult age; majority," 盛年, meaning “prime of life,” and 生年, meaning “year of birth; age.” While the last two phrases are unlikely to be what was meant on the various sites harvested for terms, it is possible that some of the sites meant the word meaning "adult age" as a means of referring to adult content. The comparatively mature content of many seinen anime also lends itself to this possibility.

\subsection{Setting}

The "setting" facet describes the environment the anime takes place in. The facet is split into three sub-facets, which represent the different aspects of setting: "setting-time," "setting-place," and "setting-situational."

The "setting-time" sub-facet contains terms that relate to the temporal aspect of setting. As such, it situates the anime in time if the anime takes place on earth or provides an equivalent time period if the anime takes place in an alternate world:

- "Historical" is for anime that take place during a past time period;

- "Steampunk" is for anime that take place in a time period where steam power is prevalent; and,

- "Cyberpunk" is for anime that take place in a future time period where advanced technology intersects an abnormal social order.

The "setting-place" sub-facet contains terms that relate to the spatial aspect of setting. As such, it provides the location the anime takes place in:

- "Isekai (parallel universe)" is for anime that take place in an alternate reality;

- "Western" is for anime that take place in the Western United States; and,

- "Space opera" is for anime that take place across an extensive expanse of interstellar space.

The "setting-situational" sub-facet contains terms relating to an abnormal state in the setting's place, time, or other characteristics. It provides a description of the aesthetic or other circumstances of the anime:

- "Fantasy" is for anime that are set in a world where some level of magic or the supernatural is present;

- "Apocalypse" is for anime that are set in a world affected by cataclysmic events;

- "Science fiction" is for anime set in a world where science and advanced technology play a role; and,

- "Dystopia" is for anime that are set in a society or world where living conditions are poor.

The "setting-time" sub-facet currently lacks a robust set of foci to describe when an anime is set. "Historical" as a 
term is rather broad, which limits its usefulness in searching for anime. More granularity in descriptors of the past would facilitate locating desired works. The hazards in breaking down the "historical" label too far are that catalogers may have difficulty identifying the proper label and searchers may locate only a small number of anime. Terms associated with "historical" must be broad enough to facilitate easy cataloging and narrow enough to communicate useful information in search results. A further difficulty will include choosing terms that encompass timebased information without also necessitating other descriptors; for example, while the term "medieval" would clearly indicate a relatively narrow set of centuries, it would also presuppose a "setting-place" facet of Europe.

"Cyberpunk," "steampunk," "western," "fantasy," and "science fiction" are all problematic because the terms have elements that fit into more than one setting sub-facet. While "cyberpunk" anime are usually set in a future "setting-time," the word also requires "setting-situational" aspects in terms of technological and societal characteristics. In other words, "cyberpunk" is not exclusively an indicator of time. Similarly, a "western" is often conceived of as being situated in the Western United States ("setting-place") in the second half of the nineteenth century ("settingtime") with certain conventions ("setting-situational"). However, as Tudor $(1974,139)$ points out, "there is no basis for assuming that a 'Western' will be conceived in the same way in every culture. The way in which the genre term is applied can quite conceivably vary from case to case." Cowboy Bebop draws from the "western" genre but is not set in the time and place of most Westerns. "Fantasy" and "science fiction" proved especially difficult to pin down as the research team's members have varied understandings of what those genres entail.

The "setting-place" sub-facet is challenging because of the variety of places available; some anime span galaxies or planets whereas other anime can be confined to a single location, such as a school. Some anime also begin in one location, but then move out to other locations. For instance, Space Patrol Luluco could potentially be said to fall under the scope of both the "school" and "space" terms. Because of this it will be necessary to determine whether only the most prevalent setting should be listed for a particular work or whether all applicable settings should be considered.

\subsection{Mood}

According to Turco (1999, 50 emphasis original), "Atmosphere is the mood of the narrative, and mood is created by means of setting (locale and surroundings in which the narrative takes place), attitude (of the narrator and of the characters in the narrative), and descriptions." In media stud- ies, mood can have two different contexts: certain atmospheres represented by a particular work (in this case, anime), or the emotional states of the audience. For example, one might want to watch an anime that has a tragic mood (former) to alleviate his or her current sad feeling (latter). In this study, mood is the emotional state of the audience in relation to the feelings an anime elicits.

While the definition suggests using adjectives for the foci terms, we use the most common forms from the data collected. Most "mood" terms are nouns when used as genre terms:

- "Psychological:" An anime emphasizing the mind, focusing on the motivations or mental states of the characters. A psychological anime often surfaces questions which initiate thought-provoking, agitated, unsettling, or disturbing feelings.

_ “'Iyashikei (healing):" Iyashikei means "healing" in Japanese. The audience feels healing and soothing. Many "iyashikei (healing)" anime have a calm and slow-paced atmosphere, depicting small delights in daily life, a tendency which overlaps with the "slice of life" focus under the "plot/narrative" facet.

An anime may trigger different moods, and through facet analysis, we can describe different moods presented in a single anime by assigning multiple foci terms. As presented in the "iyashikei (healing)" example above, the "mood" terms are often closely related to "plot/narrative" terms. Audiences often feel "healed" by watching anime with a "slice of life" plot.

\subsection{Character}

"Character" describes the figures in an anime. It covers human, non-human, and imaginary figures. There are terms referring to characters of specific occupations (e.g., "pirates," "maids," "students") and those with specific characteristics (e.g., "bishōjo [beautiful girls]," "rorikon [Lolita complex]"). Some terms describe imaginary creations as characters, such as "robots/mecha," "demons," and "vampires."

As mentioned in the research method section, considering the granularity of terms, some foci terms are used for concepts that are not identical but similar. For instance, "gangs" is used for both Mafia and Yakuza (crime groups that originated in Japan); and "monsters" is used for yōkai (supernatural creatures in Japanese folklore). Depending on local needs and collections, an information system may apply this faceted structure and decide to merge or divide similar terms. The foci terms generated from this study are not an enumerative list. The faceted structure is flexible for expansion and provides a customizable level of specificity. 
The adjustment of specificity of foci terms does not affect the nine facets identified.

\subsection{Plot/narrative}

"Plot/narrative" is defined as how the story unfolds. In literary discourses, Brooks (1984, XI) defines plot as "the design and intention of narrative, what shapes a story and gives it a certain direction or intent of meaning." Similarly, Turco $(1999,101)$ defines it as the "series of rising actions leading to the climax in a written or theatrical narrative; the thread of associated incidents that makes a story, including its beginning, middle, and end" (emphasis original). In other words, plot occurs when narratives, or accounts of events (Wolfreys, Robbins, and Womack 2016), are ordered in a certain way with a certain intention. In this regard, this facet is distinguished from "subjects" in that "plot/narrative" focuses more on the overall development of the storyline, instead of overarching themes or topics. Among the twentyone foci terms, there are six sub-terms under "romance." Some of the foci terms in this facet are:

- "Romance:" The main body of the story deals with love;

- "Romance-types:" Different types of romance;

- "Bara (boys' love for male audience):" "Romance" anime in which the main characters are both male; often created by male artists, for a male audience;

- "Shōnen ai/yaoi (boys' love):" "Romance" anime in which the main characters are both male; generally targeted towards women;

_ "Shōjo ai/yuri (girls' love):" "Romance" anime in which the main characters are both female;

- "Age gap:" Anime that shows a romantic relationship between two main characters with a significant age gap;

- "Slice of life:" A story that shows the everyday life of the characters;

- "Coming-of-age:" A story that depicts the process by which young characters grow up, by showcasing characters who make the transition naturally or who are forced to grow due to external motivations;

- "Sekai-kei:" As a neologism which has not been clearly defined, this term typically refers to a story that shows an association between two main characters' relationship and a crisis in the world, e.g., Neon Genesis Evangelion (1995);

- "Absurd:" A story that is wildly unreasonable, illogical, or inappropriate; and,

- "Gekiga (plot):" A story that is likely to be serious and mature, with realistic and darker settings.

Among these foci terms, "sekai-kei" and "gekiga (plot)" require more discussion. Unlike other foci in this faceted schema, "sekai-kei" does not have any translated meaning next to the term. The reason is that the definition of this term, "sekai-kei" itself, has not been clearly agreed upon or developed by anime communities. Thomas (2014, ii) states, "The term sekai-kei ("world-type"), a genre of subcultural narrative whose defining characteristic is the omission of a mediating social dimension between individual characters and an apocalyptic large-scale situation, has come to be used as a tool of cultural criticism pertaining to young adults of the mid-90s to the mid-2000s." Satoshi Maejima's book Sekai-kei to wa nani ka: Posuto-Eva no otaku shi further explains "sekai-kei." Maejima (translated and paraphrased by Thomas 2014, 14-15) finds that "sekai-kei" anime share some characteristics: "1. They omit the social setting, 2. What is fought and on which principle it functions is not understood, and 3. These omissions are deliberately included in order to induce sympathy for the protagonists' self-consciousness or the (often tragic) love between the protagonist and the heroine in the consumers" (emphasis original).

Other than the somewhat forced and unnatural translation "world-type," which does not mean anything specific in English, there is not a good translation to define what "sekai-kei" indicates. The fact that there is not a clear-cut consensus on what the genre means does not help the situation, either. The research on the term and discussions finally lead us to decide to keep the term as it is, "sekai-kei," a decision which may indicate a limitation of the faceted schema.

Another foci-term that needs to be discussed further is "gekiga (plot)." As a term that is often used to describe certain darker genres of manga and anime, "gekiga" originated in "the late 1960s, when new styles and approaches to content were explored by a variety of manga artists" (Brophy 2010, 130). Brophy (131) goes on to describe how "gekiga" is expressed in some of Osamu Tezuka's works:

If the earlier works invited identification with the cuddlesome, the gekiga works portend a harsh duality in their theatricalized two-facedness. Centered as so many of the stories are on the duplicitous and deceitful maneuvers of humans, the postcute effect of their visages serves to amplify the psychological mechanisms that motivate their actions. From portraits of self-disorienting quandaries of personal identity ( $\mathrm{R} u$ dovibi B, Apporo no uta, and Bombal) to investigations into self-destructive disregard for personal ethics (Tsumi to batsu [Crime and Punishment], Mu, Ningen konchu ki) to treatises on self-revelatory moments of personal enlignment (Kiribito sanka, Buddha, Hi no tori), Tezuka's characters teeter on the brink of redefinition and reincarnation (emphasis original). 
The tricky part of "gekiga" is that the term indicates two different aspects of anime, the story and the visual style. Generally, "gekiga" anime can be identified by their focus on realistic artwork and character design and their inclusion of mature and serious stories. Thus, placing the foci under a single facet does not satisfy the condition of being mutually exclusive, because the schema contains both "plot/narrative" and "production-styles." Therefore, we created two separate terms, "gekiga (plot)" and "gekiga (style)" to differentiate the nuances and place them separately under two different facets.

\subsection{Subjects}

The "subjects" facet refers to themes or topics an anime primarily conveys. The facet contains thirty-three foci terms, including "game," "cooking," "time travel," "magic," "tournaments," "politics," “work life," “crime," “arts," “superpowers," etc. One foci-term from the facet, "sports," has fourteen child terms, including "wrestling," "baseball," "gymnastics," "archery," and "ice skating," indicating the popularity of "sport"s subjects in anime. Although the foci terms listed here under "subjects" are not the complete set of topics existing in anime, they are the subjects that appeared more than one time in the databases researched. When there are more "subjects" terms retrieved in the future, they can be easily added to the current structure.

\subsection{Association with other works}

"Association with other works" describes a facet that defines connections to works that are largely referential in nature. For example, an anime falling under the facet may use a cliché gag or reference a famous manga or other entertainment work (situating historical work, as in Mushi-shi), displaying cultural connectivity between creative works. These connections often occur due to the use of manga as a basis for anime stories and production; however, it is also the case that anime can be used to display a certain rhetorical understanding of Japanese culture. Foci terms included are "parody," "novel," "comics," "manga," and "documentary."

\subsection{Feature}

Feature describes a facet that is highly specific yet increasingly general and regularly presented within anime. In a sense, these are clichés that have become descriptive of works unto themselves, such that they are, at times, the entirety of the work, rather than specific instances within the work. Still, there are also many anime where these aspects are simply inserts, presented in a narrow manner for a certain audience, with little consequence or meaning with regards to the rest of the show:
_ "Fan service:" work that contains "service"; typically, some form of sexualization of male or female characters, largely for the audience rather than the show;

- "Power suits:" Suits or other forms of mobile armor that provide characters extra power in some form-includes Gundam-type armors, but also exoskeletons and other forms of armor enhancement; and,

- "Henshin (transformation):" scenes that show off a character changing form in some way, typified by magical girl series, though before this, often included in Power Rangers and other series involving characters changing to a "powered up" form.

\subsection{Production}

"Production" represents a wide variety of terms for how the anime was created. This includes the different ways in which an anime may be brought about by way of presentation. The facet relates strongly to style visually as well as acoustically and includes a wider discussion of how length defines the varying types of anime typically created. Some of the sub-facets and foci terms are as follows:

- "Techniques:: the method for constructing the anime visually;

- "CG animation:" a visual method using digital computer graphics to render characters or environments, rather than hand-drawn animation;

- "Styles:" the normative visual representation of characters or backgrounds in the anime;

- "Chibi (super deformed):" a style defined by characters with cartoonishly large heads and much smaller bodies, often focusing on representational facial animations;

- "Gekiga (style):" a style defined by dramatic imagery, including characters in relief, often including wide panoramic shots and specific use of shadow to denote facial features;

- "Regions:" the location in which the anime is made;

- "Foreign anime:" anime developed outside of Japan or of the normative culture defining it;

- "Cartoon:" shows developed or produced with western audiences in mind, typically more stylistic than specific to location;

- "Agents:" groups or individuals involved with the production of anime;

_ "Voice actors:" individuals who provide audio for characters in anime;

- "Formats:" the structure of the anime either as it relates to length or connectedness to other works;

- “ONA (original net animation):” a typically short work produced for immediate release online, rather than other methods of broadcast; 
- "Special (SP):" a work that is typically a one-time event, presented for a specific purpose, such as a Christmas special;

- "OVA (original video animation):" a short work produced for immediate release to some fixed physical format, such as VHS, Blu-ray, DVD, or other forms of fixed media.

- "Short (length):" a short is defined both by length and presentation, typically in a trailer-like fashion, frequently presenting or expanding upon some quirk or oddity in a work;

- "Movies:” longer works presented in a non-serialized manner, often complete and standalone works, without need for connective tissue from other works or episodes; and,
- "Series:" shorter, episodic works that are connected by a consistent cast of characters, storylines and events, often culminating or building up over time.

\subsection{Facet application to existing anime}

To show how our schema can describe different genre information in anime, Table 3 shows facet and foci application to existing anime as examples. Note that multiple foci terms can be applied to each facet due to their mutual exclusivity, which makes the genre facet classification stronger by enabling users to describe anime in detail. When a specific facet of an anime is ambiguous, unclear, or cannot be described well with the current foci, it is left with $\mathrm{N} / \mathrm{A}$.

\begin{tabular}{|c|c|c|c|c|c|}
\hline & $\begin{array}{c}\text { One Punch Man } \\
\quad(2015)\end{array}$ & $\begin{array}{c}\text { Attack on Titan } \\
\text { (2013) }\end{array}$ & $\begin{array}{c}\text { Ristorante } \\
\text { Paradiso (2009) }\end{array}$ & $\begin{array}{c}\text { Ouran High School } \\
\text { Host Club (2006) }\end{array}$ & One Piece (1999) \\
\hline Audience & Seinen (Youth) & Seinen (Youth) & Josei (Women) & Shōjo (Girls) & Shōnen (Boys) \\
\hline Setting & Science Fiction & $\begin{array}{l}\text { Situational: } \\
\text { Apocalypse }\end{array}$ & $\begin{array}{c}\text { Place: } \\
\text { Restaurants/Stores }\end{array}$ & Place: School & $\begin{array}{l}\text { Situational: } \\
\text { Fantasy }\end{array}$ \\
\hline Mood & Comedy & $\begin{array}{l}\text { Tragedy; } \\
\text { Thriller; } \\
\text { Horror; } \\
\text { Suspense }\end{array}$ & Iyashikei (Healing) & Comedy & Comedy \\
\hline Character & $\begin{array}{c}\text { Hero } \\
\text { (Protagonist); } \\
\text { Cyborgs; } \\
\text { Monsters; } \\
\text { Aliens; } \\
\text { Samurai; } \\
\text { Ninja }\end{array}$ & $\begin{array}{c}\text { Hero } \\
\text { (Protagonist); } \\
\text { Monsters; } \\
\text { Hunters }\end{array}$ & $\begin{array}{c}\text { Heroine } \\
\text { (Protagonist) }\end{array}$ & $\begin{array}{c}\text { Heroine (Protagonist); } \\
\text { Students; } \\
\text { Bishōnen (Beautiful } \\
\text { Boys) }\end{array}$ & $\begin{array}{c}\text { Hero } \\
\text { (Protagonist); } \\
\text { Pirates; } \\
\text { Hybrids }\end{array}$ \\
\hline $\begin{array}{c}\text { Plot/ } \\
\text { Narrative }\end{array}$ & $\begin{array}{l}\text { Coming-of-Age; } \\
\text { Adventure }\end{array}$ & $\begin{array}{l}\text { Coming-of-Age; } \\
\text { Gekiga (Plot); } \\
\text { Survival }\end{array}$ & $\begin{array}{c}\text { Romance; } \\
\text { Romance-Types: Age } \\
\text { Gap; } \\
\text { Slice of Life; } \\
\text { Drama }\end{array}$ & $\begin{array}{l}\text { Romance; Romance- } \\
\text { Multiple People: Harem/ } \\
\text { Reverse Harem; } \\
\text { Slice of Life }\end{array}$ & $\begin{array}{c}\text { Coming-of-Age; } \\
\text { Drama; } \\
\text { Adventure }\end{array}$ \\
\hline Subjects & $\begin{array}{c}\text { Superpowers; } \\
\text { Violent Contents }\end{array}$ & $\begin{array}{c}\text { Violent Contents; } \\
\text { War; } \\
\text { Military; }\end{array}$ & $\begin{array}{l}\text { Cooking; } \\
\text { Work Life }\end{array}$ & Club & $\begin{array}{c}\text { Superpowers; } \\
\text { Violent Contents }\end{array}$ \\
\hline $\begin{array}{l}\text { Association } \\
\text { with Other } \\
\text { Works }\end{array}$ & Manga & Manga & Manga & Manga & Manga \\
\hline Feature & Action Scenes & $\begin{array}{l}\text { Action Scenes; } \\
\text { Swordplay }\end{array}$ & Fan Service & Fan Service & Action Scenes \\
\hline Production & $\begin{array}{l}\text { Formats: Series; } \\
\text { OVA (Original } \\
\text { Video Animation) }\end{array}$ & $\begin{array}{c}\text { Formats: Series; } \\
\text { OVA (Original } \\
\text { Video } \\
\text { Animation); } \\
\text { Styles: Gekiga } \\
\text { (Style) }\end{array}$ & Formats: Series & Formats: Series & $\begin{array}{l}\text { Formats: Series; } \\
\text { Movies; } \\
\text { OVA (Original } \\
\text { Video Animation) }\end{array}$ \\
\hline
\end{tabular}

Table 3. Facet application to existing anime examples. 


\subsection{Challenges and Implications}

The biggest challenge confronted was the choice of foci terms for each facet. Because anime naturally adopts Japanese culture and language to describe its genres, most English-speaking users also tend to use Japanese terms to describe anime's genres, which has become communally normative. Considering user warrant and literary warrant (Svenonius 1989), we believe the genre terms currently used by real users should be reflected in our schema for users who are already familiar with the material. Using existing terms also demonstrates respect for the culture, domain, and community.

At the same time, as we briefly discussed in the Introduction section, adopting foreign terms to the organization system thoughtlessly, especially when there are many foreign terms, may yield several serious issues. The organization system should be user-friendly to new or casual users. That is, the terms themselves used in the schema should be intuitive enough so users would not require much training to learn how to use the schema. With these conflicting goals in mind-honoring existing terms and cultures and providing an intuitive schema-we discussed three different options for term selection: using original (Japanese) terms, using English-translated terms, and using both together.

Using English-translated terms might create a more intuitive schema, especially for users who are not familiar with anime terminology. However, it would not be "friendly" to anime fans and people who are familiar with the culture already, ironically. Additionally, several terms could not be translated easily because of their complex meanings or interrelationships with either Japanese or anime culture. As examples, we discussed "gekiga" and "sekai-kei" above. The prevalence of difficult-to-translate terms is the reason we chose to use both English and Japanese, having original terms and translated terms together in our schema. Using such a method, we can keep the original terms used in the community and have a schema intuitive enough for users unfamiliar with anime jargon.

Any researchers in the knowledge organization domain will likely face linguistic issues when they attempt to build a new schema for relatively new types of information or foreign materials, including art, design, visual media, and more. We hope our approach might provide some guidelines for future research.

\subsection{Conclusion}

By harvesting genre terms from a diverse spread of online anime collections and investigating the relationships between them, we identified common types of information represented in related terms. These commonalities were condensed into general facets of genre, listing specific options as foci terms under each facet. By organizing genre terms in such a manner, our system allows each anime title to encompass multiple genres.

The faceted approach to anime genre, furthermore, reveals connections between genre terms in a way that is not necessarily visible from traditional organizational methods for genre. Traditional hierarchical methods limit genre elements to related concepts, such as broader terms or narrower terms, while our analysis reveals that genre includes more aspects than the traditionally narrow labels for genres and sub-genres. Using facets to address various aspects of a work (setting, mood, character types, etc.) demonstrates how more than one type of information can be represented in a genre organization system. Instead of restricting an anime's genre to one choice in a hierarchical system, a structure that provides multiple labels allows users to accurately represent the multi-genre nature of anime. For example, while a story that includes comedic and romantic elements might traditionally be labeled a "romantic comedy," as its own genre, that story could in our faceted approach support both a mood genre of comedy and a narrative/plot genre of romance, more clearly identifying the work's characteristics.

In addition, the faceted approach is easily applicable to formats beyond anime. Genre as a universal concept can be useful and flexible when describing existing works. Granted, multifaceted genre labels have limited usefulness within the physical space of a library or other physical collection, in that a single DVD cannot be shelved in multiple places at the same time. But, a multifaceted genre system has complete freedom within modern electronic indexing and searching systems to make works accessible to users. No matter how many different search terms or facets a user includes in a search, the database can still point the user to relevant results. A faceted system such as we propose is also easier to extend than traditional hierarchies. While a hierarchical system must flex in many directions to accommodate the addition or deletion of a term by establishing new pathways between terms, a faceted system can easily absorb new terms within various facets.

We found disparate conceptions of genre and a lack of uniformity among anime search systems restrictive to the usefulness of genre data. For users, breadth and specificity of data are desirable. A faceted system allows anime to be identified by breadth of information (in listing multiple aspects, such as setting, theme, and target audience) and by specificity of information (in selecting as many labels as necessary from within each aspect). Instead of a traditional hierarchy, a faceted approach better organizes and represents the nebulous conceptual space of genre; a faceted approach welcomes the complexity of anime works rather than limiting them to single spaces in a genre catalog. 


\section{References}

AJA (Association of Japanese Animations). 2016. "Anime Industry Report 2015.” http://aja.gr.jp/english/japananime-data

Amazon Services LLC. 2017. "Amazon.com: Movies \& TV: Anime.” Accessed July 25. https://www.amazon. com/anime-dvd-bluray/b/ref=MoviesHPBB_Genres _Anime?ie $=\mathrm{UTF} 8 \&$ node $=2650364011$

Anime-Planet (blog). 2017. "Complete List of Anime Genres and Tags." Accessed July 25. https://www.animeplanet.com/anime/tags

Breen, Jim. s.v. “青年,” Accessed July 25, 2017. “Jim Breen's WWWJDIC.” [Melbourne\}: Monash University, Electronic Dictionary Research and Development Group. http://nihongo.monash.edu/cgi-bin/wwwjdic ?1MDJ $\% \mathrm{C} 0 \% \mathrm{C} 4 \% \mathrm{C} 7 \% \mathrm{AF}$

Brenner, Robin E. 2007. Understanding Manga and Anime. Westport, CT: Libraries Unlimited.

Brophy, Philip. 2010. "Osamu Tezuka's Gekiga: Behind the Mask of Manga." In Manga: An Anthology of Global and Cultural Perspectives, ed. Toni Johnson-Woods. New York: Continuum, 128-36.

Brooks, Peter. 1992. Reading for the Plot: Design and Intention in Narrative. Cambridge, MA: Harvard University Press.

Cho, Hyerim, Marc L. Schmalz, Stephen A. Keating and Jin Ha Lee. 2017. "Information Needs for Anime Recommendation: Analyzing Anime Users' Online Forum Queries." In JCDL '17 Proceedings of the 17th ACM/IEEE Joint Conference on Digital Libraries 305-6 Toronto, Ontario, Canada_June 19-23, 2017. Piscataway, NJ: IEEE Press.

Cobley, Paul. 2005. "Objectivity and Immanence in Genre Theory." Genre Matters: Essays in Theory and Criticism, ed. Garin Dowd, Lesley Stevenson \& Jeremy Strong. Bristol: Intellect, 41-53.

"Crunchyroll - Browse Anime by Genres." 2017. Crunchyroll (blog). Accessed July 20. http://www.crunchyroll. com/videos/anime/genres

Davis, Northrop. 2016. Manga and Anime Go to Hollywood. New York: Bloomsbury Academic.

Denison, Rayna. 2015. Anime: A Critical Introduction. London: Bloomsbury Academic.

Exner, Nina. 2012. "Anime-zing in North Carolina: Library Views of Anime Fans." North Carolina Libraries 70, no. 1: 28-34.

Fennell, Dana, Ana S. Q. Liberato, Bridget Hayden, and Yuko Fujino. 2013. "Consuming Anime." Television \& New Media 14: 440-56. doi: 10.1177/1527476412436 986

Frow, John. 2006. Genre. The New Critical Idiom. London: Routledge.
"Funimation Entertainment-Genres." 2017. Funimation (blog). Accessed July 25, 2017. https://www.funimation. com/genre/

Green, Rebecca. 2017. "Facet Analysis and Semantic Frames.” Knowledge Organization 44: 397-404.

Halsall, Jane. 2004. "The Anime Revelation." School Library Journal 50, no. 8: suppl. 6-13.

Hjørland, Birger. 2013. "Facet Analysis: The Logical Approach to Knowledge Organization." Information Processing \& Management 49: 545-57.

IMDb.com, Inc. Accessed July 24, 2017a. "IMDb.com, Inc. - Browse Popular Genres.” http://www.imdb. com/feature/genre/

IMDb.com, Inc. Accessed July 24, 2017b. "Doraemon (TV Series 1973-).” http://www.imdb.com/title/tt1032831/

IMDb.com, Inc. Accessed July 24, 2017c. "My Neighbor Totoro (1988)." http://www.imdb.com/title/tt00962 83/

Kodansha's Essential Kanji Dictionary: A Compact Character Dictionary for Students and Professionals. 2002. S.v. “青.” Tokyo: Kodansha International.

Kodansha's Furigana Japanese Dictionary, Japanese-English, EnglishJapanese. 1999. S.v. “せいねん将青年.” Tokyo: Kodansha International.

La Barre, Kathryn. 2010. "Facet Analysis." Annual Review of Information Science and Technology 44: 243-84.

Lee, Jin Ha, Yuna Shim, and Jacob Jett. 2015. "Analyzing User Requests for Anime Recommendations." In JCDL '15 Proceedings of the 15th ACM/IEEE-CS Joint Conference on Digital Libraries Knoxville, Tennessee, USA-June $21=25$, 2015. New York: ACM, 269-70 doi>10.1145/ 2756406.2756969.

Levi, Antonia. 2013. "The Sweet Smell of Japan: Anime, Manga, and Japan in North America." Journal of Asian Pacific Communication 23: 3-18.

MyAnimeList, LLC. Accessed August 1, 2017. "Anime Search." https://myanimelist.net/anime.php

Poitras, Gilles. 2002. Anime Essentials: Everything a Fan Needs to Know. Berkeley, CA: Stone Bridge Press.

Poitras, Gilles. (2007) 2010. s.v. “Seinen 青年.” Anime and Manga Terminology. Retrieved from http://www.koyagi. com/Terminology.html

Rafferty, Pauline. 2012. "Epistemology, Literary Genre and Knowledge Organization Systems." In 20 Años del Capitulo Español de ISKO: Actas del X Congreso ISKO Capitulo Español, Ferrol, 30 de junio-1 de julio del 2011, ed. Pérez Pais, María del Carmen, González Bonome and María de los Ángeles. A Coruña: Universidade da Coruña, Servicio de Publicaciones, 553-65.

Ressler, Karen. 2016. "Report: Anime Industry Up 12\% in 2015." Anime News Network (blog), September 29. http://www.animenewsnetwork.com/news/2016-09- 
29/report-anime-industry-up-12-percent-in-2015/.107 055

Richmond, Simon. 2009. The Rough Guide to Anime. Rough Guides Reference. New York: Rough Guides.

Robbins, Laura Pope. 2014. "Bringing Anime to Academic Libraries: A Recommended Core Collection." Collection Building 33: 46-52.

Sardar, Ziauddin and Borin Van Loon. 2015. Introducing Media Studies: A Graphic Guide. London: Icon Books.

Shiri, Ali. 2014. "Making Sense of Big Data: A Facet Analysis Approach.” In Knowledge Organization 41: 357-68.

Slavic, Aida and Sylvie Davies. 2017. "Facet Analysis in UDC: Questions of Structure, Functionality and Data Formality." In Knowledge Organization 44: 425-35.

Smiraglia, Richard P. and Joshua A. Henry. 2016. "Facets Among the Topoi: An Emerging Taxonomy of Silent Film Music." In Knowledge Organization for a Sustainable World: Challenges and Perspectives for Cultural, Scientific, and Technological Sharing in a Connected Society: Proceedings of the Fourteenth International ISKO Conference 27-29 September 2016 Rio de Janeiro, Brazil, ed. J.A. Chaves Guimarães, S. Oliveira Milani, V. Dodebei. Advances in Knowledge Organization 15. Würzburg: Ergon, 153-60.

Spiteri, Louise F. 1998. "The Use of Facet Analysis in Information Retrieval Thesauri: An Examination of Selected Guidelines for Thesaurus Construction." Cataloging \& Classification Quarterly 25: 21-37.

Svenonius, Elaine. 1989. "Design of Controlled Vocabularies." Encyclopedia of Library and Information Science 45 (suppl. 10) , ed. Allen Kent. New York: Marcel Dekker, 82-109.

Svenonius, Elaine. 2000. The Intellectual Foundation of Information Organization. Digital Libraries and Electronic Publishing. Cambridge, MA: MIT Press.

Thomas, Stefanie. 2014. "Sekai-kei as Existentialist Narrative: Positioning Xenosaga within the Genre Framework." MA thesis., The Ohio State University.

Tudor, Andrew. 1974. Theories of Film. Cinema One 23. London: Martin Secker \& Warburg.

Turco, Lewis. 1999. The Book of Literary Terms: The Genres of Fiction, Drama, Nonfiction, Literary Criticism, and Scholarship. Hanover, NH: University Press of New England.

Vickery, B. C. 1960. Faceted Classification: A Guide to Construction and Use of Special Schemes. London: Aslib.

Viz Media, LLC. Accessed July 25, 2017. “Watch.” https:// www.viz.com/watch

Wikimedia Foundation, Inc. Accessed December 17, $2017 \mathrm{a}$. “Doraemon (1979 nen no terebi anime)." ドラえもん (1979 年のテレビアニメ). https://ja.wikipedia.org/wiki/ドラえもん_(1979年のテレビアニメ)

Wikimedia Foundation, Inc. Accessed December 17, 2017b. “Doraemon (2005 nen no terebi anime)." ドラえもん
(2005 年のテレビアニメ). https://ja.wikipedia.org/wiki/ドラえもん_(2005 年のテレビアニメ)

Wikimedia Foundation, Inc. Accessed December 17, 2017c. “Kodomomuke Anime.” 子供向けアニメ. https:// ja.wikipedia.org/wiki/子供向けアニメ\#乳幼児・幼 児向けの特徵

Wolfreys, Julian, Ruth Robbins and Kenneth Womack. 2016. Key Concepts in Literary Theory. [Abington]: Routledge.

\section{Appendix: Complete List of Anime Genre Foci Terms}

\author{
Audience \\ Josei (Women) \\ Seinen (Youth) \\ Shōnen (Boys) \\ Shōjo (Girls) \\ Kodomo (Children) \\ Family
}

Setting

Setting-Time

Cyberpunk

Steampunk

Historical

Setting-Situational

Fantasy

Apocalypse

Science Fiction

Science Fantasy

Dystopia

Setting-Place

Restaurants/Stores

Isekai (Parallel Universe)

Western

Space Opera

School

Afterlife

Space

Mood

Tragedy

Thriller

Comedy

Psychological

Horror

Suspense

Iyashikei (Healing)

Characters

Magic Idol Singers

Gangs

Detectives

Police 
Students

Idols

Maids

Pirates

Hunters

Hybrids

Trap

Cyborgs

Androids

Robots/Mecha

Bishōjo (Beautiful Girls)

Bishōnen (Beautiful Boys)

Monsters

Aliens

Vampires

Busty Females

Shotakon (Shōtarō Complex)

Rorikon (Lolita Complex)

Gender Bender

Samurai

Demons

Delinquents

Mahō Shōjo (Magical Girls)

Ninja

Gods

Angels

Hero (Protagonist)

Heroine (Protagonist)

\section{Plot/Narrative}

Sudden Girlfriend Appearance

Slice of Life

Coming-of-Age

Drama

Adventure

Mystery

Conspiracy

Sekai-kei

Absurd

Abstract

Mind-Twisting

Gekiga (Plot)

Survival

Biography

Romance

Plot/Narrative-Romance-Types

Bara (Boys' Love for Male Audience)

Shōnen Ai/Yaoi (Boys' Love)

Shōjo Ai/Yuri (Girls' Love)

Age Gap

Plot/Narrative-Romance-Multiple People

Love Triangle

Harem/Reverse Harem
Subjects

Game

Vehicles

Cooking

Time Travel

Magic

Virtual Reality

Tournaments

Politics

Sexual Contents

Violent Contents

Work Life

Body Sharing/Body Swapping/Reincarnation

Crime

Music

Arts

Natural Disaster

Amnesia

War

Military

Club

Genetic Modification

Human Enhancement

Superpowers

Otaku Culture

Abuse

Supernatural

Seishun (Youth)

Terrorism

Educational

Gambling

Mythology

Bullying

Sports

Subjects-Sports

Wresting

Baseball

Gymnastics

Boxing

Martial Arts

Archery

Fishing

Swimming

Volleyball

Ice Skating

Cycling

Soccer

Tennis

Dancing

Association with Other Works

Parody

Novel 
Comics

Manga

DocumentaryFeature

Action Scenes

Fan Service

Power Suits

Henshin (Transformation)

Feature-Action Scenes-Types

Proxy Battles

Swordplay

Gunfights

Production

Production-Techniques

CG Animation

Production-Styles

Chibi (Super Deformed)

Gekiga (Style)

\author{
Production-Regions \\ Foreign Anime \\ Cartoon \\ Production-Agents \\ Voice Actors \\ Production-Formats \\ ONA (Original Net Animation) \\ Special (SP) \\ OVA (Original Video Animation) \\ Short (Length) \\ Movies \\ Series \\ Production-Languages \\ Dubbed
}

